\title{
EFEKTIFITAS PENAMBAHAN PIPA PENGISAP PADA PROSES FLUIDISASI
}

\author{
Andi Bunga Tongeng Anas ${ }^{1)}$ Fausiah latif ${ }^{2)}$ \\ 1)Universitas Muhammadiyah Makassar, Indonesia \\ Email : bunga_tongeng@yahoo.com \\ ${ }^{2)}$ Universitas Muhammadiyah Makassar, Indonesia \\ Email :fausiahlatif574@gmail.com
}

\begin{abstract}
Abstrak
Penelitian ini bertujuan untuk meneliti pengaruh pipa pengisap pada proses fluidisasi terhadap profil alur yang terbentuk, pengaruh diameter lubang perforasi dan jarak antar lubang terhadap volume slurry yang tergelontor, dan efektifitas penggunaan pipa pengisap untuk menggelontor ke hilir. Penelitian ini bersifat eksperimen, yaitu berupa pemodelan fisik di Laboratorium Hidrolika Teknik Sipil, Fakultas Teknik, Universitas Hasanuddin, dengan uji fisik yang dilakukan di model saluran yang dilengkapi dengan pompa air, pipa fluidisasi dan pipa pengisap. Simulasi model terdiri dari dua kondisi yaitu kondisi tanpa pipa pengisap dan dengan pipa pengisap. Rancangan simulasi menggunakan variasi tekanan fluidisasi $(P)$, diameter lubang perforasi $(d)$ dan jarak antar lubang $(x)$. Debit air saluran dibuat konstan. Hasil penelitian menunjukkan bahwa penambahan pipa pengisap pada proses fluidisasi, berpengaruh secara signifikan pada alur yang terbentuk. Diameter lubang perforasi $(d)$ dan jarak antar lubang $(x)$ tersebut, juga berpengaruh terhadap besarnya volume slurry (V) yang tergelontor, di mana semakin besar diameter lubang $(d)$ maka semakin besar volume yang tergelontor $(V)$. Sementara, semakin kecil jarak antar lubang $(x)$, maka semakin besar volume yang tergelontor $(V)$. Semakin besar volume terisap dan tergelontor akibat penambahan pipa pengisap, menunjukkan bahwa penambahan pipa lebih efektif daripada fluidisasi biasa.
\end{abstract}

Kata Kunci : Fluidisasi, diameter lubang perforasi (d),volume slurry tergelontor(V)

\begin{abstract}
The aims of this study were to investigate the effect of the suction pipe of the fluidization process on formed groove profile, effect of hole perforation diameter and the distance between holes to the flowed volume slurry, as well as effectiveness of suction pipe to enable downstream flow. The nature of this research is an experimental study that concerns physical modelling at Hydraulic Civil Engineering, Engineering Faculty of Hasanuddin University. Physical test was performed with chanelling model equipped with water pump, fluidization pipe, and suction pipe. The simulation model consisted of two conditions, namely condition without suction pipe and condition with suction pipe. Design of simulation employed fluidized pressure variation $(P)$, perforation hole diameter $(d)$ and distance between the holes $(x)$. Debit of water channel was made constant. The result of research showed that addition of suction pipe at fluidization process had significant effect on the formed groove. Diameter of perforation hole (d) and distance bertween the holes $(x)$ had effect on the level of sprayed slurry volume. The greater the hole diameter $(d)$ the greater the sprayed volume $(V)$. Meanwhile, the smaller the distance between the holes, the greater the sprayed volume (V). The greater the sucked and sprayed volume as a result of additional suction pipe implies that addition of pipe is more effective than normal fluidization. [
\end{abstract}

Keywords: fluidization, perforation hole diameter (d), the volume of slurry (V)

\section{PENDAHULUAN}

Sedimen di muara sungai, merupakan masalah yang akan selalu ditemui. Muara sungai akan lebih rentan terhadap gangguan endapan lidah pasir (sand spit) bila berada pada 
daerah pantai dengan arus sedimen sejajar pantai cukup besar. Pada muara yang secara morfologi dipengaruhi oleh gelombang laut dominan yang membentuk sudut terhadap garis pantai, maka akan terjadi arus sedimen sejajar pantai dengan arah mengikuti pergerakan sedimen tersebut. Hal ini akan lebih diperparah lagi bila sungai tersebut tidak mempunyai debit yang cukup untuk menggelontor sedimen yang menumpuk di muara.

Bagian paling hilir dari muara sungai yang langsung bertemu laut disebut mulut sungai, merupakan daerah yang paling mendominasi penumpukan sedimen. Sedang estuari adalah bagian dari sungai yang dipengaruhi oleh pasang surut. Pengaruh pasang surut terhadap sirkulasi aliran (kecepatan/debit, profil muka air, intrusi air asin) di estuary dapat sampai jauh ke hulu sungai, yang tergantung pada tinggi pasang surut, debit sungai dan karakteristik estuari (tampang aliran, kekasaran dinding, dan sebagainya) (Triatmodjo, 1999).

Tingginya biaya pemeliharaan alur muara dengan pengerukan rutin, serta mahalnya biaya konstruksi dari pembangunan jetty dan underwater sill, mendorong dikembangkannya metode fluidisasi sebagai suatu alternatif penangan masalah sedimentasi baik pada alur pelabuhan, navigasi, maupun perawatan muara. Metode fluidisasi diusulkan berdasar hasil penelitian proses backwashing media filter.

Metode fluidisasi adalah metode yang menggunakan prinsip mengagitasi (mengusik) sedimen dari pipa fluidizer yang ditanam di dasar saluran (di bawah sedimen), dengan memanfaatkan pancaran air bertekanan mengakibatkan sedimen bed load berubah menjadi suspended load, yang pada akhirnya dapat mengalir secara gravitasi ke area lain yang berelevasi rendah.

Dari beberapa penelitian yang pernah dilakukan, hasil penelitian yang dilakukan oleh Ni'am dkk (2002), menghasilkan kesimpulan bahwa aliran permukaan berpengaruh secara signifikan terhadap geometri alur terutama pada lebar alur yang terbentuk. Sedangkan pengaruh terhadap kedalaman alur di hilir tidak tampak, dikarenakan aliran permukaan yang disimulasikan tidak mampu menggerus/ menggelontor slurry yang terhambat tumpukan sedimen di bagian hilir alur. Sangat kecilnya pengaruh terhadap 
geometri alur di hilir, akibat aliran permukaan yang disimulasikan tidak mampu menggerus/ menggelontor slurry yang terhambat tumpukan sedimen di bagian hilir alur, menyebabkan pengerukan alur belum maksimal.

Menurut Pristianto (2010), pengaruh ketinggian sedimen dalam pipa terhadap kebutuhan tekanan untuk membersihkan sedimen dalam proses fluidisasi, adalah semakin kecil kecepatan aliran dan semakin tingginya sedimen dalam pipa, menurunkan nilai rerata gradient tekanan pada pipa horizontal, sedangkan pada pipa vertikal terjadi peningkatan rerata gradient tekanannya.

Selain itu, meningkatnya tebal sedimen juga akan berakibat kepada semakin besar tekanan yang dihasilkan, terjadinya hal tersebut disebabkan adanya beberapa tinggi tekanan yang hilang seperti akibat gesekan pada dinding saluran, belokan pipa, lapisan sedimen, dan akibat lubang isap (Didi, 2012)

Guna memperoleh sebuah alur optimal dari proses fluidisasi, dibutuhkan sebuah peningkatan kapasitas dari metode sebelumnya. Penambahan pipa pengisap yang diletakkan di atas pipa fluidisasi, untuk bisa membantu mengisap slurry lebih banyak lagi, yang selama ini tidak semuanya tergelontor oleh aliran permukaan.

Berdasarkan hal tersebut, Penulis melakukan sebuah penelitian eksperimental, tentang peningkatan kapasitas hasil fluidisasi untuk pengerukan alur, dengan menempatkan pipa pengisap bersama pipa fluidisasi untuk memaksimalkan penggelontoran slurry. Penelitian ini bertujuan untuk meneliti efektifitas penambahann pipa pengisap pada proses fluidisasi terhadap profil alur yang terbentuk.

\section{BAHAN DAN METODE}

\section{Lokasi dan Rancangan Penelitian}

Penelitian ini dilaksanakan di Laboratorium Hidrolika Teknik Sipil, Fakultas Teknik Universitas Hasanuddin Kabupaten Gowa. Jenis penelitian adalah penelitian eksperimental dengan melakukan uji pada model fluidisasi.

\section{Variabel yang Diteliti}

Variabel yang diteliti dalam penelitian ini adalah geometri profil alur yang terbentuk setelah proses fluidisasi, volume sedimen (v) dalam bentuk slurry yang tergelontor akibat adanya penambahan pipa pengisap, yang diperikirakan dipengaruhi oleh tekanan 
fluidisasi $(\mathrm{P})$, diameter lubang perforasi (d), dan jarak antar lubang perforasi (x).

\section{Perancangan Model dan Simulasi}

Model saluran berupa flume yang dilengkapi dengan pompa, pipa fluidisasi dan pipa pengisap. Simulasi dijalankan dengan dua kondisi, yaitu fluidisasi tanpa penambahan pipa pengisap dan dengan pipa pengisap. Variasi dilakukan terhadap tekanan fluidisasi $(P)$, diameter lubang perforasi (d) dan jarak antar lubang $(x)$.

\section{Metode Analisa Data}

Pengolahan dan analisa data profil alur yang dihasilkan oleh fluidisasi, menggunakan software Surfer ver.10. Hasil olahan dengan software tersebut akan dibandingkan, antara profil geometri alur yang terbentuk sebelum menggunakan pipa pengisap dan setelah menggunakan pipa pengisap. Untuk data volume yang dihasilkan pada beberapa simulasi dengan variasi tekanan, diameter lubang perforasi dan jarak antar lubang, maka dilakukan analisa dengan membuat grafik hubungan antar variabel tersebut. Grafik hubungan tersebutlah yang akan diinterpretasikan sebagai hasil dari penelitian.

\section{HASIL}

\section{Volume Tergelontor}

Penambahan pipa dikatakan efektif, apabila ada selisih volume yang signifikan antara volume slurry yang tergelontor oleh air permukaan dan oleh pipa pengisap.

Data volume sedimen yang tergelontor, untuk tiap-tiap diameter lubang dengan tekanan fluidisasi tertentu, dapat dilihat pada tabel 1 .

\section{Tabel 1. Volume Slurry yang Tergelontor Setelah Fluidisasi}

\begin{tabular}{|c|c|c|c|c|}
\hline No & $\begin{array}{c}\text { Jarak } \\
\text { Lubang } \\
(\mathrm{cm}) \\
\end{array}$ & $\begin{array}{c}\text { Diameter Lubang } \\
(\mathbf{m m}) \\
\end{array}$ & $\begin{array}{c}\text { Tekanan Fluidisasi } \\
\left(\mathrm{kg} / \mathrm{cm}^{2}\right) \\
\end{array}$ & 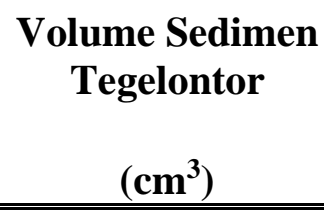 \\
\hline 1 & & & 0.4 & 1331.6 \\
\hline 2 & & $\begin{array}{l}\text { - anpa pipa } \\
\text { nenoisan }\end{array}$ & 2.2 & 1331.6 \\
\hline 3 & & & 3.8 & 1331.6 \\
\hline 4 & & & 0.4 & 961.7 \\
\hline 5 & & 3 & 2.2 & 896.4 \\
\hline 6 & 5 & & 3.8 & 325.7 \\
\hline 7 & 5 & & 0.4 & 6023.2 \\
\hline 8 & & 4 & 2.2 & 7297.2 \\
\hline 9 & & & 3.8 & 8112.2 \\
\hline
\end{tabular}




\begin{tabular}{|c|c|c|c|c|}
\hline 10 & & & 0.4 & 10672 \\
\hline 11 & & 6 & 2.2 & 7205.8 \\
\hline 12 & & & 3.8 & 11559.3 \\
\hline 13 & & & 0.4 & 710.2 \\
\hline 14 & & 3 & 2.2 & 1242.85 \\
\hline 15 & & & 3.8 & 710.2 \\
\hline 16 & & & 0.4 & 3413.1 \\
\hline 17 & 7 & 4 & 2.2 & 7127.3 \\
\hline 18 & & & 3.8 & 5725.2 \\
\hline 19 & & & 0.4 & 3349.5 \\
\hline 20 & & 6 & 2.2 & 3891.9 \\
\hline 21 & & & 3.8 & 8668.6 \\
\hline 22 & & & 0.4 & 26.63 \\
\hline 23 & & 3 & 2.2 & 26.63 \\
\hline 24 & & & 3.8 & 44.39 \\
\hline 25 & & & 0.4 & 1596.5 \\
\hline 26 & 9 & 4 & 2.2 & 1137.9 \\
\hline 27 & & & 3.8 & 1466 \\
\hline 28 & & & 0.4 & 2711.9 \\
\hline 29 & & 6 & 2.2 & 5347.4 \\
\hline 30 & & & 3.8 & 6499.4 \\
\hline
\end{tabular}

\section{Profil Alur Yang Terbentuk dengan}

\section{Penambahan Pipa Pengisap}

Profil yang terbentuk dari proses fluidisasi menunjukkan bahwa semakin besar tekanan fluidisasi, maka semakin besar hasil pengerukan alur akibat slurry yang tergelontor.
Profil alur terbesar yang dihasilkan oleh proses fluidisasi dengan pipa pengisap, diperoleh pada simulasi dengan menggunakan pipa berlubang yang memiliki diameter lubang $(d)$ terbesar, yaitu $6 \mathrm{~mm}$. Hal ini dapat dilihat pada gambar 1 . 


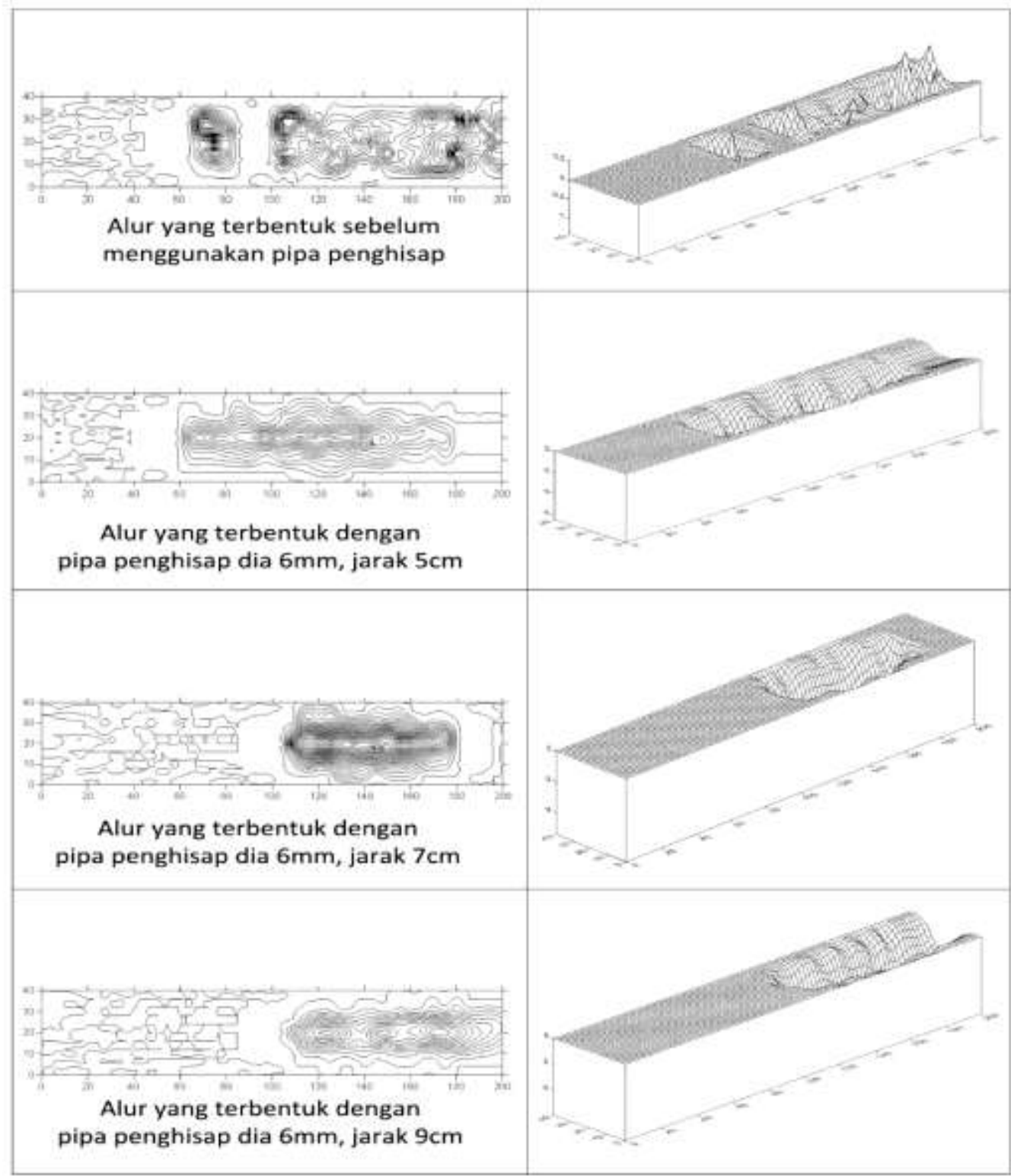

Gambar 1. Perbandingan Alur yang Terbentuk Dengan Pipa Pengisap Diameter Lubang Perforasi 6 mm

Adapun variasi jarak antar lubang $(x)$ yang menghasilkan profil alur terbesar, adalah pada jarak sebesar $5 \mathrm{~cm}$. Profil yang terbentuk dari jarak tersebut, pada dilihat pada gambar 2. 


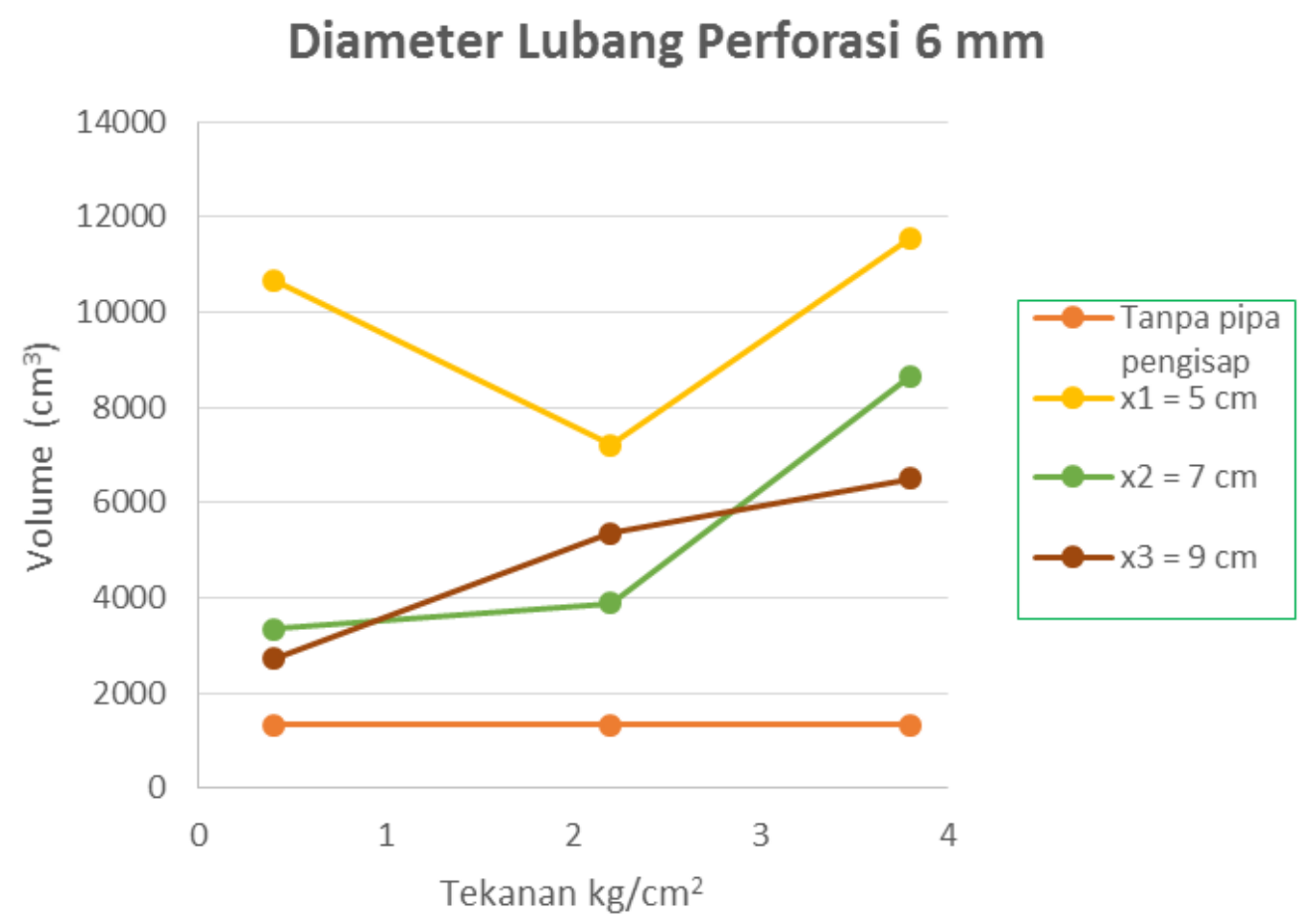

Gambar 2. Hubungan Tekanan Fluidisasi dan Volume Terisap, Untuk Tiap-tiap Jarak Antar Lubang Dengan Diameter Lubang 6 mm

$\begin{array}{ll}\text { Hubungan Diameter Lubang } & \text { gambar 3. Di mana volume terbesar } \\ \text { Perforasi dan Jarak Lubang } & \text { yang tergelontor dihasilkan pada pipa } \\ \text { Terhadap Volume Tergelontor } & \text { dengan diameter lubang } 6 \text { mm. } \\ \text { Simulasi pada model dengan } 3 & \text { sedangkan untuk jarak antar lubang, } \\ \text { variasi diameter lubang dan } 3 \text { variasi } & \text { maka volume tergelontor yang } \\ \text { jarak antara lubang, menghasilkan } & \text { terbesar dihasilkan pada pipa dengan } \\ \text { data grafik seperti dilihat pada } & \text { jarak lubangnya sebesar } 5 \mathrm{~cm} .\end{array}$




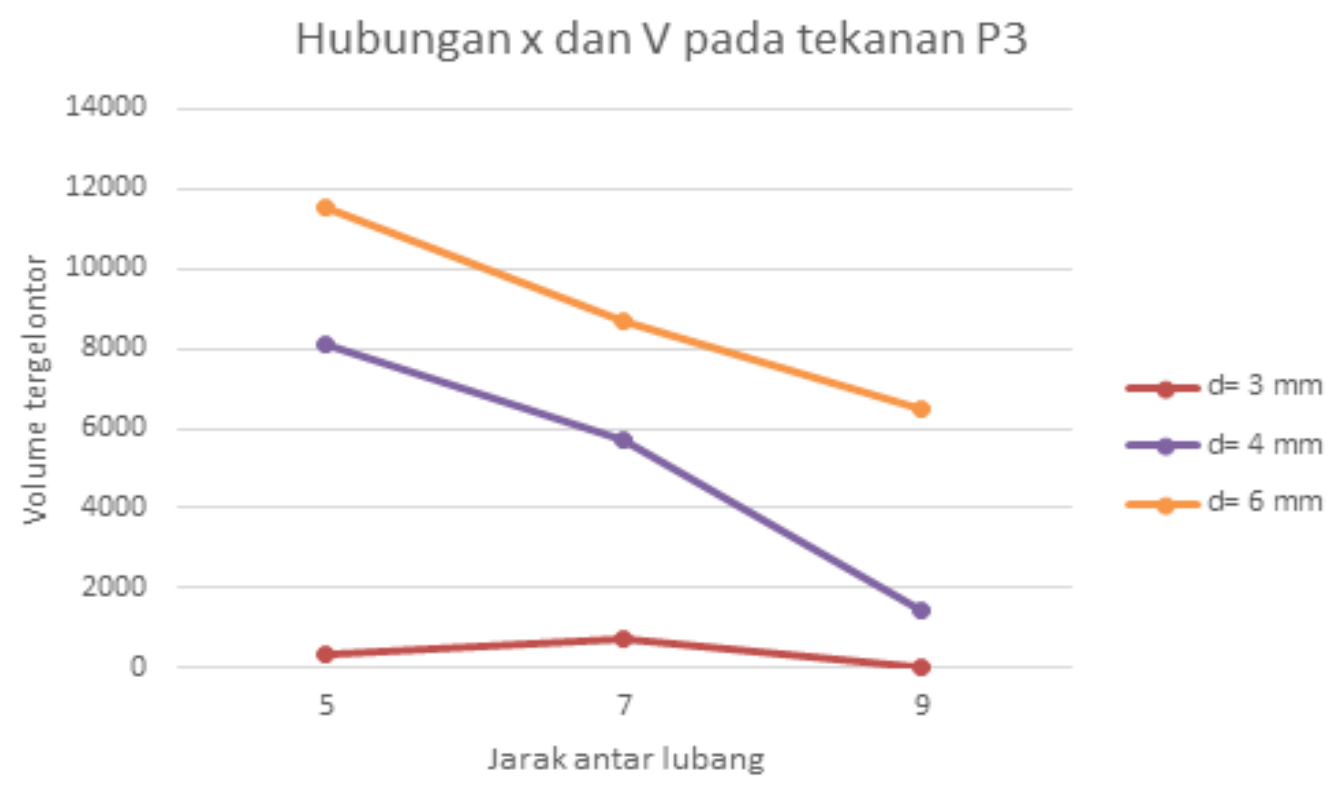

Gambar 3. Hubungan Jarak Antar Lubang Perforasi Dengan Volume Tergelontor pada Tekanan P3

Gambar 4 yang menunjukkan semakin kecil jarak antar lubang, hubungan $\mathrm{x} / \mathrm{d}$ dan $\mathrm{Vo} / \mathrm{V}$, menyatakan maka semakin besar pula volume bahwa semakin besar diameter dan slurry yang dapat digelontorkan.

\section{Hubungan $\mathrm{x} / \mathrm{d}$ dan $\mathrm{Vo} / \mathrm{V}$}

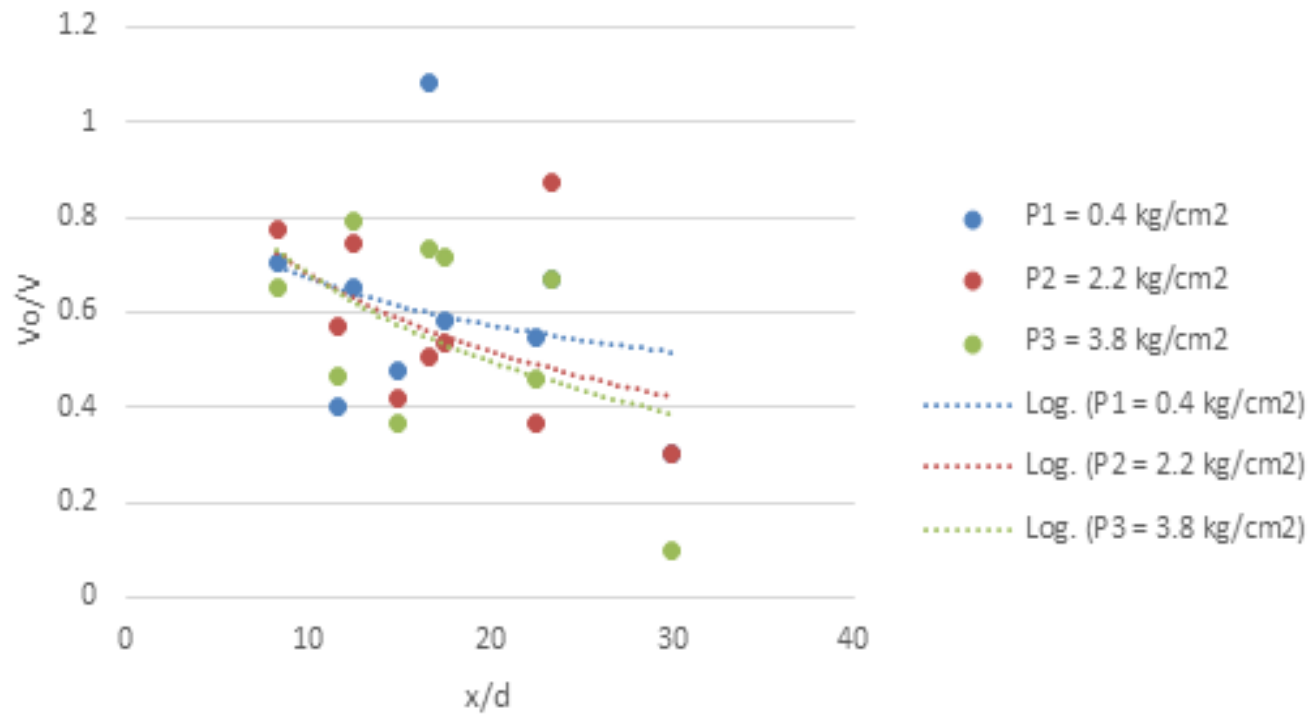

Gambar 4. Hubungan $\mathrm{x} / \mathrm{d}$ dan $\mathrm{Vo} / \mathrm{V}$ 


\section{PEMBAHASAN}

Penelitian ini menunjukkan bahwa dari ketiga variasi tekanan, maka pengaruh pipa pengisap terhadap profil alur yang terbentuk adalah paling optimal diperoleh pada tekanan terbesar. Sehingga dapat dikatakan bahwa semakin besar tekanan fluidisasi, maka semakin banyak volume slurry. Menurut Ni'am dkk (2004), kebutuhan tekanan di dalam pipa akan bertambah seiring dengan bertambahnya ketebalan sedimen yang akan difluidisasi, berpengaruh secara signifikan terhadap geometri alur yang terbentuk.

Besarnya volume bed load yang mampu terusik/teragitasi tergantung pada besarnya tekanan fluidisasi dalam pipa. Tekanan yang besar akan menyebabkan besarnya volume slurry yang terbentuk dan memudahkan pipa pengisap untuk mengisap slurry dan membuangnya ke lokasi tertentu. Besarnya volume yang terbuang akibat pengisapan akan membentuk geometri alur yang lebih besar daripada hasil fluidisasi biasa.
Penelitian lebih lanjut terkait kebutuhan tekanan fluidisasi, juga telah diteliti oleh Faisal (2010), dimana diperoleh bahwa kebutuhan tekanan untuk awal fluidisasi maksimal adalah 10 kali tebal sedimen dan untuk mencapai kondisi full fluidisasi maksimal dibutuhkan tekanan sebesar 20 kali tebal sedimen. Thaha (2006), menyatakan bahwa ada dua faktor penting yang berpengaruh dalam perencanaan teknis fluidisasi yaitu tenaga air (energi head) yang dibutuhkan untuk mengangkut sedimen dan dimensi alur optimal yang dapat dihasilkan (geometric elements).

Besarnya lebar alur yang terbentuk akibat fluidisasi tak hanya dipengaruhi oleh tekanan fluidisasi saja, Ni'am (2003), menyatakan bahwa lebar alur yang terbentuk dari proses fluidisasi dipengaruhi oleh kedalaman penanaman pipa atau ketebalan sedimen $\left(d_{b}\right)$. Hal ini berarti bahwa semakin dalam penempatan pipa, maka akan semakin besar sedimen yang menjadi slurry, sehingga memudahkan untuk 
mengisap sedimen lebih banyak dan membentuk alur yang lebih lebar.

Faktor lain yang mempengaruhi hasil dari fluidisasi sehingga tidak mampu menghasilkan slurry yang optimal adalah aliran gravitasi dan juga terjadinya penyumbatan (clogging) pada lubang perforasi pipa fluidisasi (Prasojo, 2001). Hal ini tentunya dapat pula terjadi pada pipa pengisap yang penempatan lubang perforasinya juga dibuat dalam posisi horizontal.

Dharma dkk (2005), menyatakan dalam penelitiannya bahwa diameter lubang, jarak lubang dan posisi lubang dengan aliran permukaan memiliki pengaruh terhadap hasil dari fluidisasi. Sebagaimana halnya pada pipa fluidisasi, maka pipa pengisap yang akan digunakan untuk mengisap slurry untuk digelontorkan ke lokasi tertentu, memiliki diameter lubang perforasi dan jarak antar lubang tertentu.

Model pipa pengisap pada penelitian ini menggunakan diameter lubang perforasi (d) sebesar $3 \mathrm{~mm}, 4$ $\mathrm{mm}$ dan $6 \mathrm{~mm}$. Untuk masingmasing diameter tersebut, divariasikan lagi jarak antar lubangnya $(x)$, yaitu jarak $5 \mathrm{~cm}, 7 \mathrm{~cm}$ dan $9 \mathrm{~cm}$.

Pengaruh diameter lubang dan jarak antar lubang perforasi terhadap volume tergelontor, menunjukkan pengaruh yang signifikan pada diameter lubang $6 \mathrm{~mm}$. Sementara untuk jarak antar lubang, pengaruh signifikan terhadap volume terisap dan tergelontor dapat terjadi pada pipa jarak antar lubang sebesar $5 \mathrm{~cm}$. Sehingga dapat disimpulkan bahwa semakin besar diameter pipa maka akan semakin besar pula volume slurry yang dapat digelontor ke hilir.

Penelitian ini menunjukkan bahwa tekanan yang besar, diameter lubang yang besar, namun dengan jarak lubang yang rapat pada pipa pengisap, mampu menggelontorkan volume slurry yang besar. Sehingga penambahan pipa pengisap pada proses fluidisasi dapat dikatakan efektif untuk menggelontor sedimen ke hilir.

Untuk menghasilkan geometri alur yang optimal dibutuhkan sebuah proses fluidisasi yang optimal, bantuan pipa pengisap untuk mempercepat dan memperbesar 
pembuangan slurry dan sistem flusing conduit. Flushing conduit sendiri merupakan pengembangan dari metoda fluidisasi yang dalam mekanisme prosesnya didahului oleh proses fluidisasi (menaikkan tekanan dalam pipa) kemudian setelah sedimen teragitasi dilakukanlah proses flushing (penurunan tekanan dalam pipa) sehingga sediman terisap masuk kedalam pipa dan dialirkan memalui pipa flushing menuju ke bagian hilir pipa (Didi, 2011).

\section{KESIMPULAN DAN SARAN}

Disimpulkan bahwa terdapat pengaruh pipa pengisap terhadap alur yang terbentuk, paling optimal pada penggunaan pipa dengan diameter lubang perforasi $6 \mathrm{~mm}$ dan jarak antar lubang $5 \mathrm{~cm}$. Semakin besar tekanan fludisasi, maka semakin tebal sedimen yang dapat terusik, dan semakin besar volume dari slurry yang mampu diisap oleh pipa pengisap. Perpaduan semakin besar diameter lubang dan semakin kecilnya jarak antar lubang, akan menghasilkan alur yang optimal. Efektifitas penggunaan pipa pengisap pada proses fluidisasi, untuk memperbesar dimensi alur yang terbentuk, dengan jalan memperbesar volume slurry yang terbuang, dapat dihasilkan dengan memperbesar dimensi lubang perforasi dan menempatkannya dalam jarak yang saling berdekatan. Disarankan untuk penelitian berikutnya, menguji fluidisasi pipa pengisap dengan debit yang divariasikan. Pengukuran dan variasi tekanan isap, juga perlu dilakukan penelitian lebih lanjut.

\section{DAFTAR PUSTAKA}

Dharma B., Yuwono N., \& Nizam (2005). Pengaruh Diameter Lubang, Jarak Lubang dan Posisi Lubang Fluidisasi Dengan Aliran Permukaan Pada Metode Fluidisasi. Jurnal Teknosains XVIII (1).

Didi A. B. (2012). Kajian Parameter Sedimen yang Berpengaruh Terhadap Volume Sedimen Tergelontor Pada Metoda Flushing, Jurnal Universitas Muhammadiyah Pare-Pare. Diakses 19 Mei 2014. Available from http://www.umpar.ac.id/jurn al_detail.php?

Didi A. B. (2011). Kajian Sistem Pengaturan Tekanan Dalam Pipa Pada Metode Flushing Conduit Untuk Pemeliharaan Alur (Tesis). Makassar: Universitas Hasanuddin. 
Faisal. (2010). Pengaruh Dimensi Lubang Perforasi Terhadap Fluidisasi Sedimen Berbutir Kasar (Tesis). Makassar: Universitas Hasanuddin.

Ni'am M. F. (2003). Kebutuhan Debt Pada Proses Fluidisasi Sedimen Non Kohesif Untuk Penanganan Pendangkalan Muara Sungai. Jurnal Pondasi vol. 9 no.1.

Ni'am M. F., Triatmaja R., \& Nizam. (2002). Simulasi Fluidisasi Dasar Pada Saluran Dengan Aliran Permukaan Untuk Perawatan Muara dan Alur Pelayaran (Tesis). Yogyakarta: Universitas Gajah Mada

Ni'am M. F., Triatmaja R., \& Nizam. (2004). Kebutuhan Tinggi Tekanan Pada Proses Fluidisasi Untuk Mengatasi Pendangkalan Muara Sungai. Jurnal Pondasi vol. 10 no.2.

Prasojo T. (2001). Metode Fluidisasi Sedimen Non Kohesif Pada Muara Pelabuhan (Tugas Akhir). Mataram: Universitas Negeri Mataram.

Pristianto H. (2010). Flushing System sebagai Sistem Pembersihan Pipa Fluidisasi Pada Teknologi Pemeliharaan Alur Muara Sungai. Jurnal Median Vol II Nomor 2.

Thaha M.A. (2006). Sistem Fludisasi Untuk Rekayasa Pemeliharaan Alur (Disertasi). Yogyakarta: Universitas Gadjah Mada.

Triatmojo B. (1999). Teknik Pantai. Yogyakarta: Penerbit Beta Offset. 